\title{
IMPROVING POWER SYSTEM QUALITY USING FLEXIBLE AC TRANSMISSION SYSTEMS*
}

\author{
Ahmed A. H. Mohamed and Mohamed R. S. Abdul-aal** \\ Electrical Engineering Department., El Minia University, Egypt.
}

\begin{abstract}
This paper presents detailed fast control characteristics and continuous compensation capability; Flexible AC Transmission System (FACTS) devices have been researched and adopted in power engineering area. There are so many advantages of FACTS device; it can increase dynamic stability, loading capability of lines, improve power quality and system security. It can also increase utilization of lowest cost generation. The key role of FACTS device is to control the power flow actively and effectively. In other words, it can transfer power flow from one line to another within its capability.

This paper presents detailed improving power system quality using advanced flexible AC transmission systems (FACTS) controllers, namely, Advanced Thyristor Controlled Series Capacitors (ATCSCs), Advanced Thyristor Controlled Series Reactor (ATCSR), Advanced Static Var Compensator (ASVC) and Advanced Static Var System (ASVS). This paper focuses on the operation of the FACTS device under generator fault that may cause any other transmission lines to be overflowed. The proposed algorithm in this paper is tested on the IEEE 30 bus system.
\end{abstract}

KEY WORDS: FACTS, ATCSCs, ATCSR, ASVC, ASVS, IEEE 30 bus system.

\section{AMELIORATION DE LA QUALITE SYSTEME D'ALIMENTATION UTILISATION FLEXIBLE CA SYSTÈMES DE TRANSMISSION}

\section{RÉSUMÉ}

Cet article présente les caractéristiques détaillées de contrôle rapide et la capacité de compensation continue; Flexible AC Transmission System (FACTS) dispositifs ont été étudiés et adoptés dans la zone de l'ingénierie électrique. Il ya tant d'avantages du dispositif de FACTS, il peut augmenter la stabilité dynamique, capacité de chargement de lignes, d'améliorer la qualité de l'énergie et la sécurité du système. Il peut également accroître l'utilisation de la génération la moins coûteuse. Le rôle clé du dispositif de FACTS est de contrôler le flux de puissance active et efficace. En d'autres termes, il peut transférer des flux de puissance d'une ligne à une autre au sein de sa capacité.

Ce document présente en détail améliorer la qualité du système d'alimentation à l'aide de pointe CA flexible des systèmes de transmission (FACTS) contrôleurs, à savoir, avancée Condensateurs Thyristor série contrôlée (ATCSCs), Advanced Thyristor Controlled Series Reactor (ATCSR), Advanced statique Var Compensateur (ASVC) et Advanced Var statique Système (ASVS). Ce document se concentre sur le fonctionnement des dispositifs faits sous la faute génératrice qui peut causer des lignes de transmission d'autres d'être débordé. L'algorithme proposé dans ce papier est testé sur le système de bus IEEE 30.

MOTS CLÉS: FAITS, ATCSCs, ATCSR, ASVC, ASVS, SYSTÈMES BUS IEEE 30.

\footnotetext{
* Received: 26/12/2010, Accepted:17/1/2011 (Review Paper)

** Contact Author (0185108423)
} 


\section{INTRODUCTION:}

Studies of power quality phenomena have emerged as an important subject in recent years due to renewed interest in improving the quality of the electricity supply. As sensitive electronic equipment continues to proliferate, the studies of power quality will be further emphasized [1].

There are two main means for improving power quality:

- The cost-free improving power quality.

- Not cost-free improving power quality.

The cost-free means for improving power quality include actions like:

- Operation of tap changing transformers.

- Operation of conventional compensating devices.

- Control by FACTS devices.

Flexible AC Transmission Systems abbreviated by FACTS forms a new domain in power system control engineering, using power electronic devices and circuits and the more recent available technologies in automatic control and valves.

The two main objectives of FACTS are:

1. To increase transmission capacity of lines.

2. Control power flow over designated transmission, electronically and statically, without need of operator's actions and without need of mechanical manipulations or conventional breakers switching.

The collapse points are known as maximum loadability points, the voltage collapse problem can be restated as an optimization problem where the objective is to maximize certain system parameters typically associated to load levels [2, 3, 4, and 5]. Hence, voltage collapse techniques may also be used to compute the maximum power that can be transmitted through the transmission system, also known in the new competitive energy market as Total Transfer Capability (TTC) [6]. It is well known that shunt and series compensation can be used to increase the maximum transfer capabilities of power networks [7]. With the improvements in current voltage handling capabilities of power electric devices that have allowed for the development of FACTS, the possibility has arisen of using different types of controllers for efficient shunt and series compensation. Thus, FACTS controllers based on thyristor controlled reactors (TCRs), such as Thyristor Controlled Series
Reactors (TCSRs) and Thyristor Controlled Series Capacitors (TCSCs), are being used by several utilities to compensate their systems [8]. More recently, various types of controllers for shunt and series compensation, based on voltage source inverters (VSIs), Shunt and Series Static Synchronous Compensators (STATCOMs and SSSCs) and Unified Power Flow Controllers (UPFCs), have been proposed and developed [9].

In [10], the authors used standard voltage collapse analysis tools to study the effect of the maximum load margin on the location of a given SVC; an approximate SVC model is used for the computations. In [11], the authors used approximate SVC and TCSC models together with typical collapse computational tools and optimization techniques to determine the appropriate location and size of these controllers; dynamic simulations using more detailed models are then performed to study the effect of these controllers in the overall stability of the network. In [12] power quality is related to balancing of the unbalanced three-phase load voltages and line currents, while improving load power-factors to unity and performing load voltages regulation, this can be achieved by using (FACTS). In [13] an approach to locate, and size the Static Var Compensator (SVC) using modal analysis in a power system in order to increase the Steady State Voltage Stability (SSVS) margin.

The proposed algorithm in this paper is tested and verified on the IEEE 30 bus system by using ATP simulation program.

\section{CONSIDERATION ON POWER QUALITY}

The nonlinear characteristics of various office and industrial equipment connected to the power grid could cause electrical disturbances leading to poor power quality. These electrical disturbances could destroy certain sensitive equipment connected to the grid or in some cases could cause them to malfunction. There is virtually no piece of office or industrial equipment that does not depend on electricity in some form or other. Among the office equipment are computers, fax machines, copiers, and telephones etc. Computers have dominated the work place while the others in modern days have microprocessors. 
All these electronic equipment when connected to the power system can actually generate electrical disturbances, which can adversely affect other equipment within the power network. Heavy industrial equipment such as nonlinear variable speed drives powered through power electronic converters cause the power disturbances. The transient problems such as sags and swells when repeatedly experienced can damage electronic equipment connected to the network.

These problems are sometimes unpredictable, because they may happen any where at any time. High-speed and modern communications allow internet monitoring. Monitoring the system needs to be done periodically at regular interval, otherwise it may become too late to take a corrective action and save the equipment connected to the system.

Both electric utilities and end users of electrical power are becoming increasingly concerned about the quality of electric power. There are many reasons for this growing concern such as; the use of microprocessor-based controls and power electronic devices. In fact many loads are sensitive to different types of disturbances.

Any power problem is manifested in voltage, current, or frequency deviations. A failure or misoperation of customer equipment means that there is a power quality problem.

\section{STEADY STATE COMPENSATOR}

There are several FACTS devices used in power system, some of them are already installed in the power system and in operation. Those devices can be categorized into 3 groups. One group in category is series compensators TCSR, TCSC. Another group is shunt compensators such as SVC, STACOM. The last one is combined compensators like UPFC.

Among those compensators, series compensators are adapted in [14] because it shows highly cost efficient characteristics in controlling the active power flow.

The use of FACTS devices to improve the power transfer capability in a high voltage transmission line is of greater interest these days [15]. In [16] a residue factor method used to obtain the optimal location of TCSC device to damp out the inter-area mode of oscillations.

\subsection{Theory}

In the case of a no-loss line, voltage magnitude at receiving end is the same as voltage magnitude at sending end:

$$
\mathrm{V}_{\mathrm{s}}=\mathrm{V}_{\mathrm{r}}=\mathrm{V} \text {. }
$$

Transmission results in a phase lag $\delta$ that depends on line reactance $\mathrm{X}$.

As it is a no-loss line, active power $\mathrm{P}$ is the same at any point of the line:

$$
\begin{aligned}
\mathrm{P}_{\mathrm{s}} & =\mathrm{P}_{\mathrm{r}}=\mathrm{P} \\
& =(\mathrm{V} \cos (\delta / 2))((2 \mathrm{~V} \sin (\delta / 2)) / \mathrm{X}) \\
& =\left(\mathrm{V}^{2} \sin \delta\right) / \mathrm{X}
\end{aligned}
$$

Reactive power at sending end is the opposite of reactive power at receiving end:

$$
\begin{aligned}
\mathrm{Q}_{\mathrm{s}} & =-\mathrm{Q}_{\mathrm{r}}=\mathrm{Q} \\
& =(\mathrm{V} \sin (\delta / 2))((2 \mathrm{~V} \sin (\delta / 2)) / \mathrm{X}) \\
& =\left(\mathrm{V}^{2}(1-\cos \delta)\right) / \mathrm{X}
\end{aligned}
$$

As $\delta$ is very small angle, active power mainly depends on $\delta$ whereas reactive power mainly depends on voltage magnitude.

\subsection{Series FACTS}

FACTS for series compensation modify line impedance: the total transmission system reactance $\mathrm{X}$ is decreased so as to increase the transmittable active power. However, more reactive power must be provided.
$\mathrm{P}=\left(\mathrm{V}^{2} \sin \delta\right) /\left(\mathrm{X}-\mathrm{X}_{\mathrm{c}}\right)$
$\mathrm{Q}=\left(\mathrm{V}^{2}(1-\cos \delta)\right) /\left(\mathrm{X}-\mathrm{X}_{\mathrm{c}}\right)$

This can be done by one of the following two methods.

\subsubsection{Advanced thyristor controlled series capacitor (ATCSC):}

It is a capacitive reactance compensator which consists of a series capacitor bank shunted by thyristor controlled reactor TCR, in order to provide a smoothly variable series capacitive reactance $\mathrm{X}_{\mathrm{C}}$. ATCSC components are given in Fig.1. 


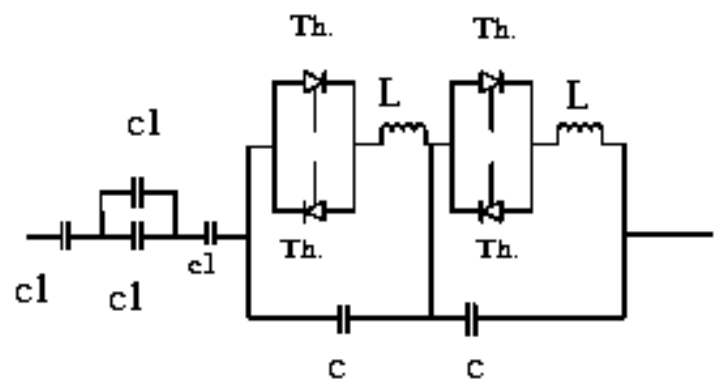

$\mathrm{c}=1 \mathrm{~F}, \quad \mathrm{c} 1=0.1 \mathrm{~F}, \quad \mathrm{~L}=1 \mathrm{H}, \quad$ Th.: $\quad$ Vig=3V, Ihold $=0.1 \mathrm{~A}$, Tdeion $=0.0001 \mathrm{sec}$.

Fig.1 Advanced Thyristor Controlled Series Capacitor (ATCSC)

\subsubsection{Advanced thyristor controlled series reactor $(\mathrm{ATCSR})$ :}

It is an inductive reactance compensator, which is composed of a series reactor, shunted by a thyristor-controlled reactor TCR, in order to provide a smoothly variable series inductive reactance. Series fixed reactor is provided to have continual service during control periods. ATCSR components are given in Fig.2.

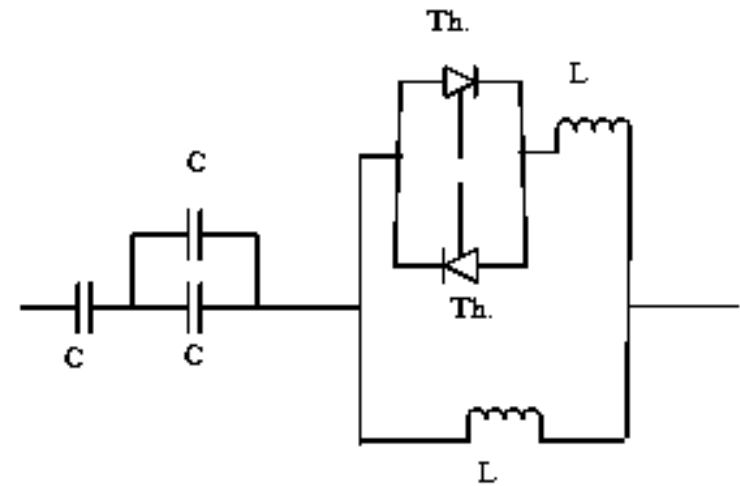

$c=0.07 \mathrm{~F}, \mathrm{~L}=0.001 \mathrm{H}$, Th.: $\mathrm{Vig}=3 \mathrm{~V}$, Ihold=0.1A, Tdeion $=0.0001 \mathrm{sec}$.

Fig.2 Advanced Thyristor Controlled Series Reactor (ATCSR)

\subsection{Shunt FACTS}

Reactive current is injected into the line to maintain voltage magnitude. Transmittable active power is increased but more reactive power is to be provided.

\subsubsection{Advanced static VAR compensators (ASVC):}

The thyristor-controlled shunt compensator is called Advanced Static VAR compensator (ASVC). The ASVC has the big advantages of fast response and energy conversion with low losses. ASVC components are given in fig.3.

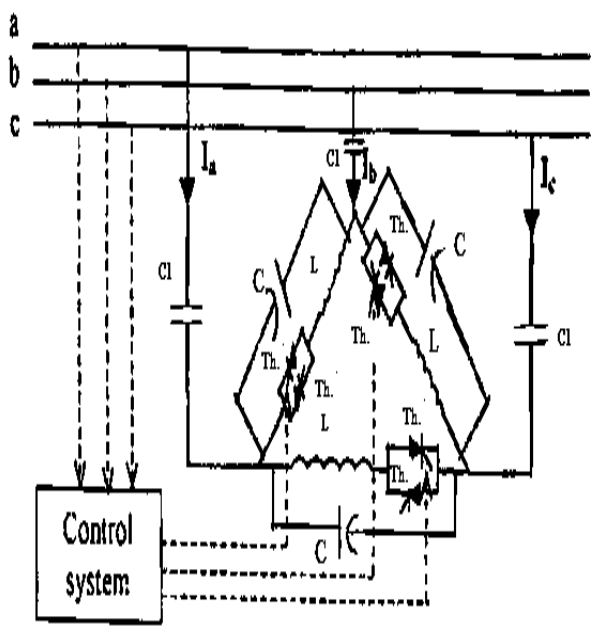

$\mathrm{c}=0.8 \mathrm{~F}, \quad \mathrm{c} 1=0.045 \mathrm{~F}, \quad \mathrm{~L}=1 \mathrm{H}, \quad$ Th.: $\quad \mathrm{Vig}=3 \mathrm{~V}$, Ihold $=0.1 \mathrm{~A}$, Tdeion $=0.0001 \mathrm{sec}$.

Fig.3 Advanced Static VAR Compensators (ASVC)

\subsubsection{Advanced static VAR system (ASVS):}

It is Advanced Static VAR System (ASVS) as a combination of Advanced Static VAR Compensator (ASVC) and mechanically switched capacitor (MSC) and mechanically switched reactors (MSR). ASVS components are given in fig. 4 .

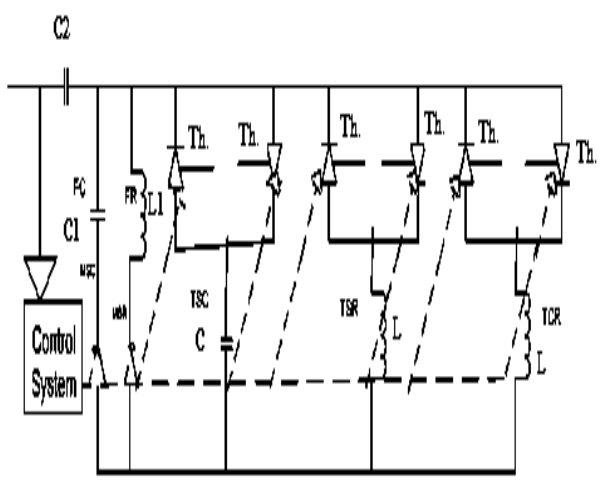

$\mathrm{c}=0.8 \mathrm{~F}, \mathrm{c} 1=1 * 10^{-20} \mathrm{~F}, \mathrm{~L}=1 \mathrm{H}, \mathrm{L} 1=1 * 10^{-6} \mathrm{H}$ Th.: Vig $=3 \mathrm{~V}$, Ihold $=0.1 \mathrm{~A}$, Tdeion $=0.0001 \mathrm{sec}$.

Fig.4 Advanced Static VAR System (ASVS) 


\section{SYSTEM UNDER STUDY SIMULATION}

\subsection{IEEE 30 bus system}

Fig.5 shows IEEE 30 bus system under study. ATP simulation program is used. The ratings of FACTS components enter to ATP program used are shown in FACTS figs. Fig.6 shows the voltage at bus 3 at normal state from 0 to 0.2 sec. $($ voltage $=27.3 \mathrm{Kvolt})$ and when generator connected to bus 1 is out of service from 0.2 to 0.4 sec. (voltage $=16.25 \mathrm{Kvolt}$ ) and when connected Advanced Thyristor Controlled Series Capacitor (ATCSC) at bus 3 from 0.4 to $0.6 \mathrm{sec}$. and the voltage increased to the normal state $($ voltage $=27.3 \mathrm{Kvolt}$ ). Fig.7 shows the voltage at bus 3 at normal state from 0 to 0.2 sec. and when generator connected to bus 1 is out of service from 0.2 to $0.4 \mathrm{sec}$. and when connected Advanced Thyristor Controlled Series Reactor (ATCSR) at bus 3 from 0.4 to $0.6 \mathrm{sec}$. and the voltage increased to the normal state (voltage $=27.3 \mathrm{~K}$ volt). Fig. 8 shows the voltage at bus 3 at normal state from 0 to 0.2 sec. and when generator connected to bus 1 is out of service from 0.2 to $0.4 \mathrm{sec}$. and when connected Advanced Static VAR System (ASVS) at bus 3 from 0.4 to $0.6 \mathrm{sec}$. and the voltage increased to the normal state (voltage $=27.3 \mathrm{Kvolt}$ ). Fig.9 shows the voltage at bus 3 at normal state from 0 to $0.2 \mathrm{sec}$. and when generator connected to bus 1 is out of service from 0.2 to $0.4 \mathrm{sec}$. and when connected Advanced Static VAR Compensator (ASVC) at bus 3 from 0.4 to $0.6 \mathrm{sec}$. and the voltage increased (voltage $=27.3 \mathrm{~K}$ volt).

In fig.6 and fig. 7 series FACTS are connected in system and connect ATCSC when needed smoothly variable series capacitive reactance in system and connect ATCSR when needed smoothly variable series inductive reactance in system. In fig.8 and fig.9 shunt FACTS are connected in system and connect ASVS when needed to connect mechanically switched capacitor (MSC) and mechanically switched reactors (MSR) in system. Voltage is offset when generator connected to bus 1 is out of service and after connect FACTS because of DC component in network and generator connected to bus 1 (out of service) is designed to absorb DC component in network.

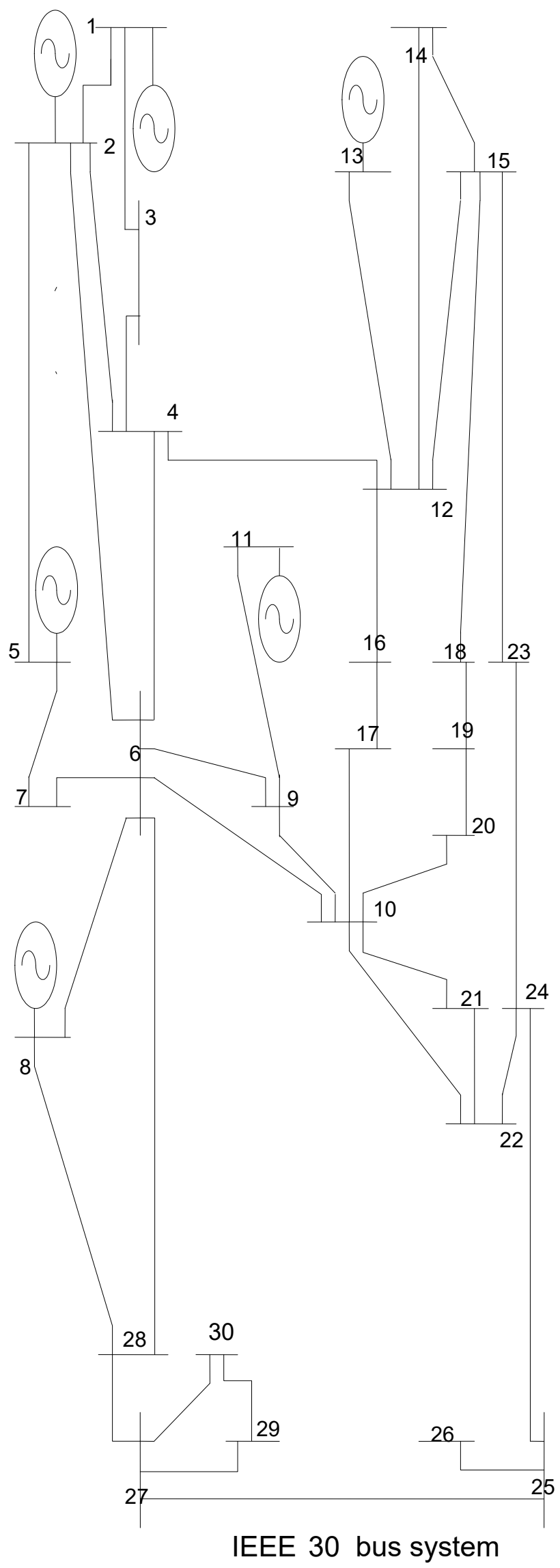

Fig.5 IEEE 30 bus system 


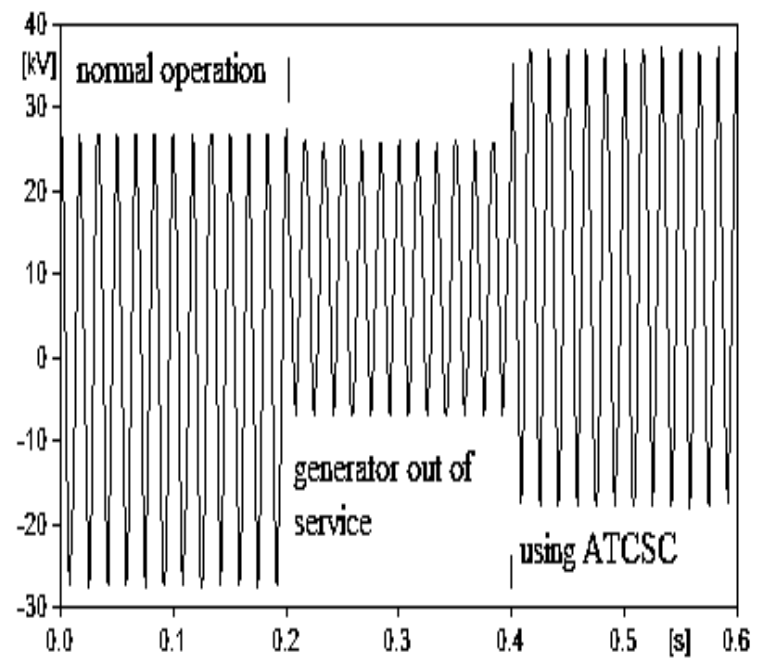

Fig.6 The Voltage at Bus 3 at Normal State in Case of Generator out of Service, Using (ATCSC)

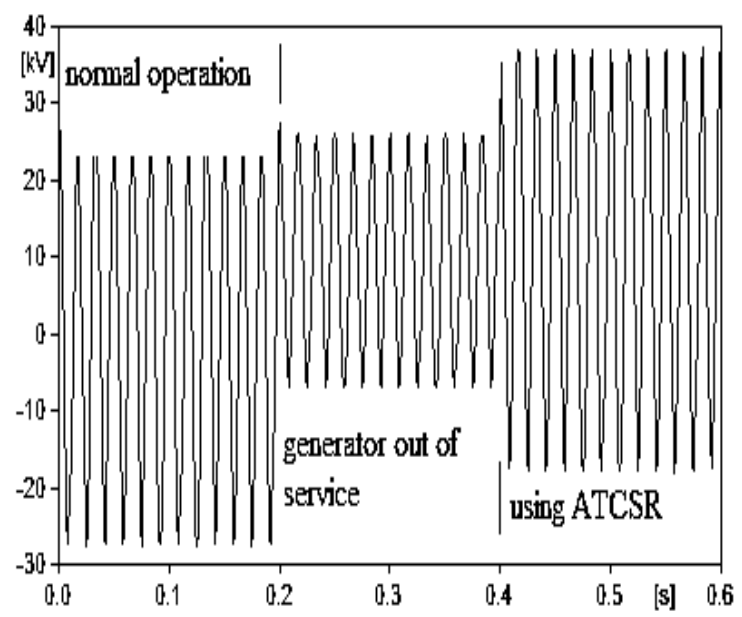

Fig.7 The Voltage at Bus 3 at Normal State in Case of Generator out of service, Using (ATCSR)

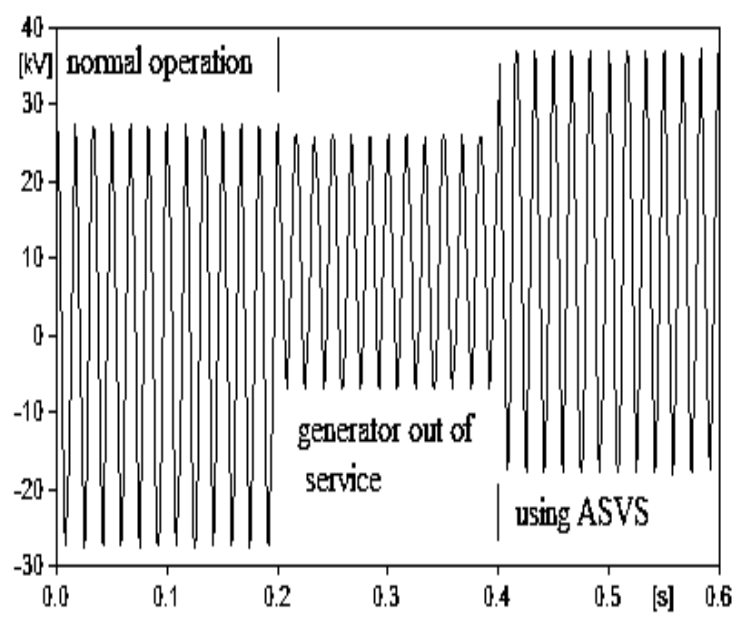

Fig.8 The Voltage at Bus 3 at Normal State in Case of Generator out of Service, Using (ASVS)

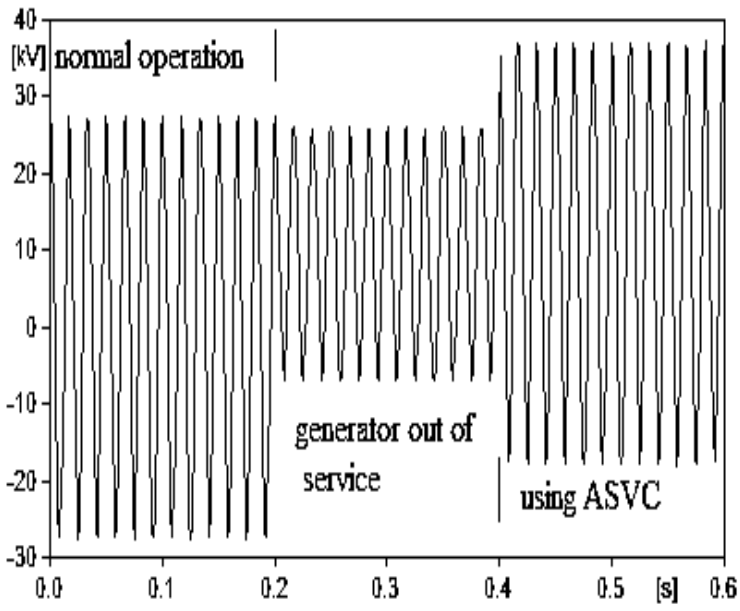

Fig.9 The Voltage at Bus 3 at Normal State in Case of Generator out of service, Using (ASVC)

Fig.10 shows the voltage at bus 2 at normal state from 0 to $0.2 \mathrm{sec}$. (voltage $=27.3 \mathrm{Kvolt}$ ) and when generator connected to bus 2 is out of service from 0.2 to $0.4 \mathrm{sec}$. and the voltage is decreased (voltage $=11.2 \mathrm{Kvolt}$ ) and when connected Advanced Thyristor Controlled Series Capacitor (ATCSC) at bus 2 from 0.4 to $0.6 \mathrm{sec}$. and the voltage increased to the normal state (voltage $=27.3 \mathrm{Kvolt}$ ).

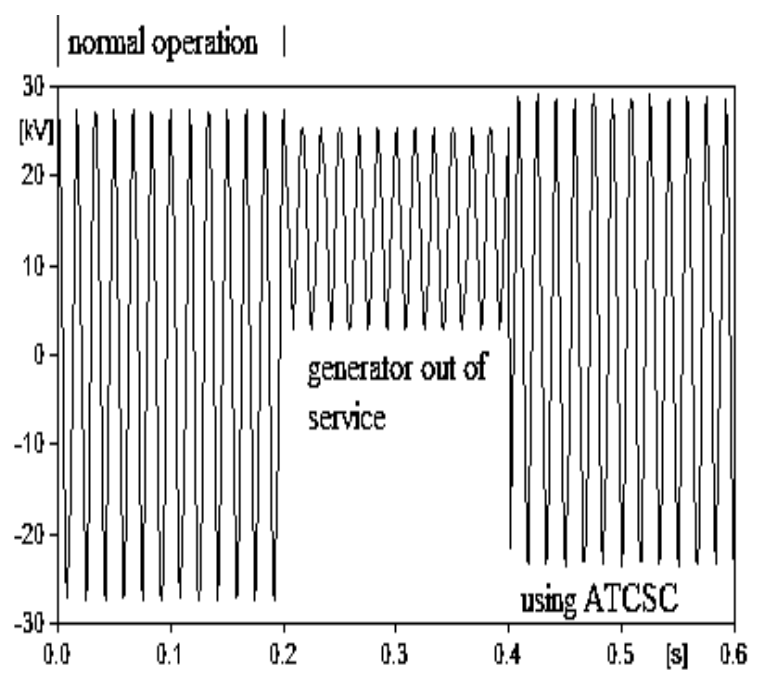

Fig.10 The Voltage at Bus 2 at Normal State in Case of Generator out of Service, Using (ATCSC)

Fig. 11 shows the voltage at bus 2 at normal state from 0 to $0.2 \mathrm{sec}$. and when generator connected to bus 2 is out of service from 0.2 to 0.4 sec. and when connected Advanced Thyristor Controlled Series Reactor (ATCSR) at bus 2 from 0.4 to $0.6 \mathrm{sec}$. and the voltage increased to the normal state (voltage $=27.3 \mathrm{Kvolt})$. 


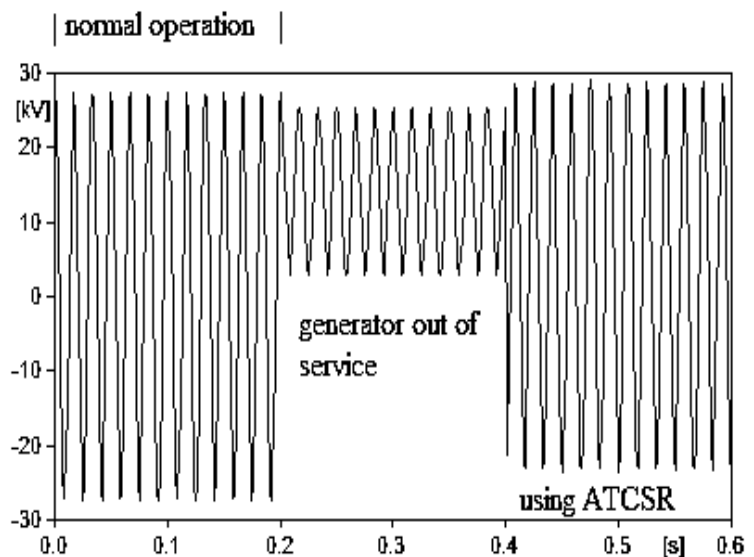

Fig.11 The Voltage at Bus 2 at Normal State in Case of Generator out of Service, Using (ATCSR)

Fig.12 shows the voltage at bus 2 at normal state from 0 to $0.2 \mathrm{sec}$. and when generator connected to bus 2 is out of service from 0.2 to $0.4 \mathrm{sec}$. and when connected Advanced Static VAR System (ASVS) at bus 2 from 0.4 to 0.6 sec. and the voltage increased to the normal state $($ voltage $=27.3 \mathrm{Kvolt})$.

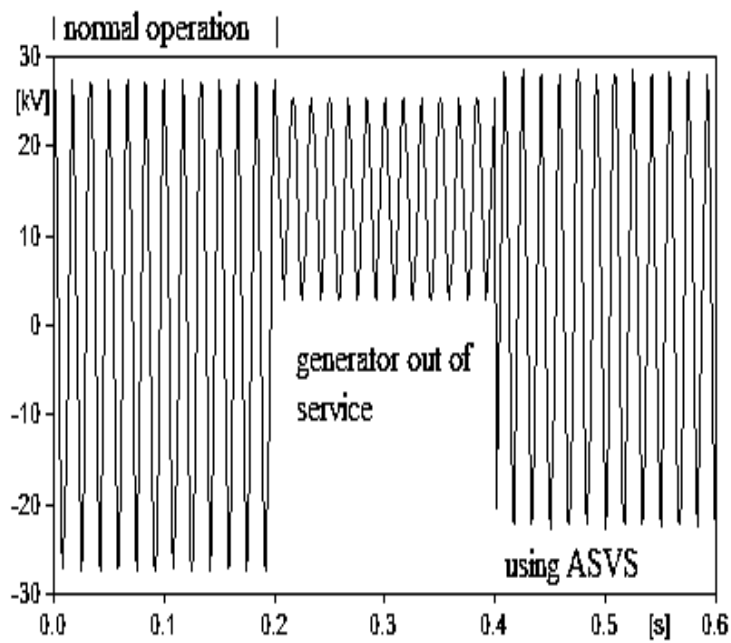

Fig.12 The Voltage at Bus 2 at Normal State in Case of Generator out of Service, Using (ASVS)

Fig.13 shows the voltage at bus 2 at normal state from 0 to $0.2 \mathrm{sec}$. and when generator connected to bus 2 is out of service from 0.2 to $0.4 \mathrm{sec}$. and when connected Advanced Static VAR Compensator (ASVC) at bus 2 from 0.4 to 0.6 sec. and the voltage increased (voltage $=27.3 \mathrm{Kvolt}$ ).

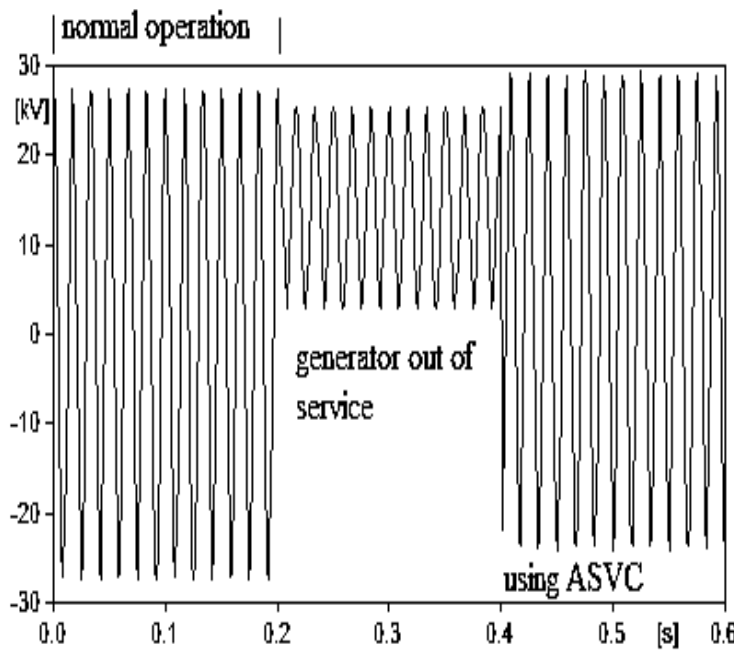

Fig.13 The Voltage at Bus 2 at Normal State in Case of Generator out of Service, Using (ASVC)

In fig.10 and fig.11 series FACTS are connected in system and connect ATCSC when needed smoothly variable series capacitive reactance in system and connect ATCSR when needed smoothly variable series inductive reactance in system. In fig. 12 and fig. 13 shunt FACTS are connected in system and connect ASVS when needed to connect mechanically switched capacitor (MSC) and mechanically switched reactors (MSR) in system. Voltage is offset when generator connected to bus 2 is out of service and after connect FACTS because of DC component in network and generator connected to bus 2 (out of service) is designed to absorb DC component in network.

\section{CONCLUSION}

In this paper, ATCSC, ATCSR, ASVS, and ASVC are only used to study for the IEEE 30 bus power system. The optimal location to connect FACTS is the bus need to improve power quality and rating of these FACTS devices to improve the power quality is shown in FACTS figs., the ATP simulation program can be used. The Alternative Transient Program (ATP) techniques use power flow calculation has several advantages such as fast calculation, possibility of determination of the margin of power quality problem. The best type of FACTS used to improve power quality is ATCSC because of fixed series capacitors shunted by thyristor controlled reactor are provided so as to guarantee service continuity during control actions. 


\section{REFERENCES}

[1] Mohamed Ramadan, 2004, "Power quality detection and classification by using modern computer techniques" Master thesis, ain shams university, Faculty of engineering, Egypt.

[2] T. Van Cutscm, February 1991,"A method to compute reactive power margins with respect to voltage collapse" IEEE Trans. Power Systems, vol. 6, no. 1, pp. 145-156.

[3] J. Lu, C. W. Liu, and J. S. Thorp, May 1995, "New methods for computing a saddle-node bifurcation point for voltage stability analysis". IEEE Trans. Power Systems, vol. 10, no. 2, pp. 978-989.

[4] C. J. Park, I. F. Morrison, and D. Sutanto, August 1996,"Application of an optimization method for determining the reactive margin from voltage collapse in reactive power planning," IEEE Trans. Power Systems, vol. 11, no. 3 , pp. $1473-1483$.

[5] C. A. Canizares, May 1997,"Calculating optimal system parameters to maximize the distance to saddle-node bifurcations," accepted for publication in the IEEE Trans. Circuits and Systems I.

[6] R. P. Klump and T. J. Overbye, November 1996, "A transmission-based voltage stability measure for available transfer cabability (atc) calculation," Proc. NAPS, MIT, pp. 351-357.

[7] A. R. Bergen, 1986, Power Systems Analysis. Prentice-Hall, New Jersey.

[8] D. Maratukulam, editor, March 1992, Proc. FACTS Conference I the Future in High-voltage Transmission, TR-100504, EPRI.

[9] L. Gyugyi, April 1994,"Dynamic compensation of ac transmission lines by solidstate synchronous voltage sources," IEEE Trans. Power Delivery, vol. 9, no. 2, pp. 904-911.

[10] Y. Mansour, W. Xu, F. Alvarado, and C. Rinzin, May 1994,"SVC placement using critical modes of voltage instability," IEEE Trans. Power Systems, vol. 9, no. 2, pp. 757763.
[11] L. A. S. Pilotto, W. W. Pinr, A. R. Carvalho, A. Wey, W. F. Long, F. L. Alvarado, C. L. DeMarco, and A. Edris, January 1997, "Determination of needed facts controllers that increase asset utilization of power systems," IEEE Trans. Power Delivery, vol. 12, no. 1, pp. 364-371.

[12] M.Z.El Sadek, et al, MEPCON'2001,"Flexible AC Transmission Systems (FACTS) for power quality improvement of unbalanced systems suffering from voltage instability", University of Helwan, Cairo, Egypt.

[13] Mohamed A. H. El-sayed, et al, mepcon'2003,"Power system voltage stability improvement by SVC", the ninth international middle-east power systems conference, Egypt.

[14] Douglas J. Gotham, Feb. 1998, "Power Flow Control and Power Flow Studies for Systems with FACTS Devices," IEEE Trans. Power Systems, vol. 13, no.1.

[15] P.K.Dash, S.R. Samantaray, and Ganapati Panda, Jan. 2007, "Fault Classification and Section Identification of an Advanced SeriesCompensated Transmission Line Using Support Vector Machine", IEEE Trans. Power Delivery, vol. 22 , no. 1 .

[16] Nuraddeen Magaji and M. W. Mustafa, May 2009,"Optimal Location of TCSC Device for Damping Oscillations", ARPN Journal of Engineering and Applied Sciences, vol. 4, no. 3. 